\title{
Biased Technological Shocks, Relative Wage Rigidities and Low-Skilled Unemployment*†
}

\author{
Olivier Pierrard ${ }^{1,2}$ and Henri R. Sneessens ${ }^{2}$ \\ ${ }^{1}$ Central bank of Luxembourg \\ ${ }^{2}$ Department of Economics, Université catholique de Louvain
}

October 3, 2007

\footnotetext{
* Part of this work was done while visiting Cepremap, Paris. Pierre Cahuc, David de la Croix, Bruno Van der Linden and Etienne Wasmer provided very helpful criticism on a previous version of the paper. We are also grateful for the comments of seminar participants at the Université catholique de Louvain, the workshop "Job competition" in Louvain-la-Neuve, the EEA congress in Venice, the EEA Summer School in Lisbon and the EALE congress in Paris. This research is part of a project financed by the Service des Etudes et de la Statistique (SES) of the Walloon Region, Belgium. We also benefited from the financial support of the PAI-UAP federal research programme P5/10/28. The views expressed in the paper represent those of the authors and not necessarily those of the Bank.

${ }^{\dagger}$ Corresponding author: Olivier Pierrard, Central bank of Luxembourg, Bd Royal 2, L-2983 Luxembourg, olivier.pierrard@bcl.lu, phone: +352 47744449 , fax: +352 47744920.
} 


\begin{abstract}
The contrast between the evolution over the last decades of the EU and the US unemployment rates, especially for the low-skilled, is well known. A consensus view is that these different outcomes can be explained by the interactions between common shocks and specific institutional setups. In this paper, we emphasise the interactions between technological changes and wages rigidities. We construct a fully calibrated general equilibrium model with two types of jobs and two types of workers, and with search unemployment. Our simulations show that with wage rigidities, technological changes suffice to generate a continuous rise in the low-skilled unemployment rate and an almost unchanged high-skilled unemployment rate. Without wage rigidities, the unemployment rates remain unchanged but the wage dispersion widens.
\end{abstract}

Keywords: unemployment, skill biased changes, wage rigidities

JEL classification: E24, J24, J31 


\section{Introduction}

The contrast between the US and EU countries in terms of unemployment is well known. In the US, there is no trend (if any, it is negative) over the period 1960-2000, although the unemployment rate remained abnormally large during the eighties and early nineties. In Europe, we start in the early sixties with low unemployment rates (around 2-3\% in France or Germany, that is approximately half the US unemployment rate at the same period), but it starts increasing in the seventies and currently remains high in a majority of countries (more than $8 \%$ in France and Germany for instance). The rules governing the labour market (the so-called "labour market institutions") are of course quite different in the US compared to most EU countries: limited social security provisions (especially unemployment insurance), decentralised wage negotiation, ... However, most economists agree today that such institutional differences alone cannot explain these differences. Many European countries were already enjoying well-developed welfare systems in the late sixties, well before the unemployment rise. It is also difficult to explain US-EU differences by countryspecific shocks. Most economic shocks (oil shocks, disinflation, introduction of new technologies, ...) were common to all countries.

Against this background, the consensus view is that the observed variety of outcomes can only be explained by the interaction between specific institutional setups and common shocks. Despite the difficulty of measuring "institutions" and "shocks", empirical work has accumulated convincing evidence supporting this point of view (see for instance Nickell (1997), Blanchard and Wolfers (2000) or Bertola, Blau, and Kahn (2001)). The institutional parameters emphasised by these studies as most important for aggregate employment are the generosity of the unemployment insurance system and the centralisation of the wage setting process whereas employment protection measures have no clear effect on aggregate employment. Within a general equilibrium job market matching framework, Den Haan, Haefke, and Ramey (2001) provide evidence of the negative effects of TFP growth, real interest rate and tax rate on employment, when institutions are not "employment friendly" (high replacement ratio). Ljungqvist and Sargent (2002, 2004) emphasise the role of higher firing costs and more generous unemployment benefits to explain the weak performance of European labour market in face of higher economic turbulence. They assume that the adoption of more and more sophisticated and complex technologies accelerated the loss of human capital when unemployed (loss of on-the-job training). In an economy with low employment protection and low unemployment benefits, job turnover is high (unemployment duration spell is short) and the human capital loss is not crucial. At the opposite end, in an economy with high employment protection and generous benefits, there is long average unemployment duration and 
the loss of human capital can become problematic. Our paper relates directly to this general equilibrium literature but provides an alternative explanation, by emphasising the interactions between the skill biased technological shocks and the wage formation mechanisms.

If the last decades have been characterized in many EU countries by a substantial increase in the average unemployment rate, this average figure hides dramatic differences across skill groups. The increase has remained fairly small for high-skilled workers, while it is usually considerable for the least skilled groups. There is ample evidence suggesting that technological progress and other related factors (organizational change, capital-skill complementarities, etc...) may have substantially increased the relative demand for skilled workers (see for instance Autor, Katz, and Krueger (1998), Berman, Bound, and Machin (1998), and Machin and Van Reenen (1998)). If not followed by an increase in the supply of skilled workers and/or compensated by relative wage adjustments, such a net demand change leads to a deterioration of the employment conditions for the low-skilled ${ }^{1}$. To study these questions, we construct a dynamic general equilibrium model similar to that of Merz (1995) and Andolfatto (1996), with endogenous capital and interest rates, and search frictions on the labour market. In this way, we are able to capture the interactions between exogenous shocks and capital accumulation, and to introduce search unemployment. We then extend this model to distinguish two types of workers (low- and high-skilled workers). The final goods production function is specified as a Cobb-Douglas function, as in standard dynamic macroeconomic models, but simply extended to distinguish the two types of workers. In this setup, biased technological change can be introduced as an exogenous change in the coefficients of the Cobb-Douglas function, implying an exogenous change in the relative demand for high- and low-skilled labour. This formulation is in line with econometric estimates of the technological bias as reported for instance in Manacorda and Petrongolo (1999).

The model is then calibrated on the Belgian economy and used to try to reproduce the continuous rise in low-skilled unemployment over the last decades ${ }^{2}$. Sneessens and Shadman (2000) provide empirical estimations of the skill biased technological changes in Belgium over the period 1976-1996, as well as changes in the relative labour supply (proportion of the skilled population). We introduce these two shocks into our model under two alternative assumptions. Under the first assumption, high wages are Nash-bargained and low wages are indexed ${ }^{3}$. Under the second assumption, both

\footnotetext{
${ }^{1}$ See Appendix 1 for the evolutions of unemployment rates (by skills) and relative wages over the last 30 years in several countries.

${ }^{2}$ Unemployment rate changes observed in Belgium over the last twenty five years have been close to those observed on average at the European level. The analysis of the Belgian case may thus provide insights for other countries as well.

${ }^{3}$ This indexation can be explained by powerful unions, collective agreements, ... This assumption is close to what
} 
types of wages are Nash-bargained. Our simulations show that under the first assumption, these shocks suffice to generate a continuous rise in the low-skilled unemployment rate and an almost unchanged high-skilled unemployment rate, as observed between 1976 and 1996. They also generate a rise in job competition (more low-skilled jobs are held by high-skilled) that seems realistic given the estimations of Hartog (2000). Under the second assumption, we can no longer reproduce these facts and instead have unchanged unemployment rates and higher wage dispersion. In this paper, we therefore emphasise the interactions between skill-biased technological shocks and relative wage rigidities to explain the high European unemployment rate.

Mortensen and Pissarides (1999) examine the consequences of a skilled-bias technological change in a model with matching frictions and a continuum of skill levels. If the economic value of nonemployment is the same for all skill groups, the wage-productivity ratio will be higher for the less productive workers, implying a higher equilibrium unemployment rate on the corresponding segment of the labor market. A skill-biased technological change exacerbates these differences, by increasing the unemployment rate of less skilled workers and decreasing that of high-skilled workers. The authors focus on the case where the labor market is perfectly segmented, so that there is no job competition across skill groups, and all wages are determined by Nash bargaining. This type of model can be extended to include job competition effects with two skill groups and two types of jobs as in Albrecht and Vroman (2002) or Gautier (2002). Job competition is introduced by allowing high-skilled job seekers to search simultaneously on the complex and the simple job markets. When hired on a simple job, they continue searching for a (better-paid) complex job. These models provide important insights on the externalities associated to matching processes and on their implications for technological change and job competition mechanisms but, because of their simplicity, they are not able to reproduce the evolution of relative unemployment rates over the last decades.

Unlike these papers, we allow for endogenous search intensities for high-skilled job seekers (determined by expected utility maximization) and for relative wage rigidities. Moreover, unlike many other search models, skilled and unskilled labour are no more perfect substitutes and we instead assume a more realistic elasticity of substitution (elasticity equal to one rather than infinity). It also implies that the marginal productivity of each job is decreasing. Finally, we embed our model in a fully calibrated general equilibrium model and produce a quantitative estimation of the effects of a skill biased technological shock. The simulation results are compared to real data.

The rest of the paper is organized as follows. Section 2 is devoted to the description of firm and we observe in most European countries, see Appendix 1. 
household behaviour and market mechanisms (matching processes, wage bargaining). We next (section 3) calibrate the model and examine its properties through comparative static simulation exercises. Section 4 concludes with a few remarks.

\section{The Model}

There are two broad categories of agents: households and firms. We assume a single representative household. All members of the household supply inelastically one unit of labour. These consumerworkers may however have different skill levels (low- or high-skilled workers); they may be employed or unemployed ${ }^{4}$.

We distinguish three types of firms: two types of intermediate good firms, producing respectively high- and low-tech intermediate goods with labour as sole input ${ }^{5}$, and one representative final firm, combining capital and the two intermediate goods to produce an homogeneous final good. The final good can be either consumed or accumulated by the representative household. The production of high-tech intermediate goods involves complex tasks that can only be carried out by skilled labour. The production of low-tech intermediate goods is made up of simpler tasks that can be carried out by both low- or high-skilled workers. We allow for this flexibility (rather than perfectly segmented labour markets) because this "de-qualification" possibility has been highlighted by several studies as an important feature of European labour markets ${ }^{6}$.

There are three types of markets: labour, goods and capital. On the labour side, we distinguish the complex and the simple job markets. For each type of job, we assume an exogenous job destruction rate and represent the matching process by a standard matching function. Because they know that their application will always be turned down, low-skilled job seekers never apply for complex jobs. High-skilled unemployed workers may look for both types of jobs, but allocate their search time on each market so as to maximize expected utility ${ }^{7}$. High-skilled workers hired on a simple job

\footnotetext{
${ }^{4}$ This representative household formulation amounts to assuming that workers are perfectly insured against unemployment risk. This simplification is common in the literature (see for instance Merz (1995) or Andolfatto (1996)) and reflects the current state of the art. Taking into account worker heterogeneity due to imperfect insurance markets would make the model totally intractable. By simplicity, we also assume one representative household with both high- and low-skilled rather than two different representative households (one of high-skilled and one of lowskilled). This simplification does not affect the results as long as welfare is not studied.

${ }^{5}$ The main motivation to the introduction of single job intermediate firms is to keep a tractable representation of the wage bargaining process.

${ }^{6}$ See for instance Dolado, Felgueroso, and Jimeno (2000), Gautier (2002) or Albrecht and Vroman (2002) for a similar representation.

${ }^{7}$ Both the low- and the high-skilled can apply for a simple job. Although the intermediate firm may have a
} 
may continue searching for a complex job ${ }^{8}$. On-the-job search intensity is again determined by expected utility maximisation. All goods markets (the two intermediate goods and the final goods markets) are assumed to be perfectly competitive. The price of the final good is normalized to one. On the capital market, the supply is determined by the stock of capital previously accumulated by the household. The interest rate adjusts to make the quantity demanded by the representative final firm equal to this predetermined capital stock.

Labour market flows are detailed in the next subsection. We then successively discuss firm and household behaviour, and the wage determination process.

\subsection{Labor Market Flows}

Let $N_{t}^{c}$ and $N_{t}^{s}$ represent the total number of complex and simple jobs respectively. Simple jobs can be occupied by high- $\left(N_{t}^{s h}\right)$ or low-skilled $\left(N_{t}^{s l}\right)$ workers, so that $N_{t}^{s}=N_{t}^{s h}+N_{t}^{s l}$. Normalizing the total labour force to one and denoting $\alpha$ the (exogenous) proportion of high-skilled workers yields the following accounting identities:

$$
N_{t}^{c}+N_{t}^{s h}+U_{t}^{h}=\alpha, \quad \text { and } \quad N_{t}^{s l}+U_{t}^{l}=1-\alpha,
$$

where $U_{t}^{h}$ and $U_{t}^{l}$ denote the number of high- and low-skilled unemployed job-seekers respectively. Let the number of complex and simple job matches be denoted by $M_{t}^{c}$ and $M_{t}^{s}$ respectively. We assume that the number of such matches is a function of the number of corresponding job vacancies $\left(V_{t}^{c}\right.$ and $V_{t}^{s}$ ) and effective job seekers (number of job seekers corrected by search efficiencies), that is, we use the following two matching functions:

$$
M_{t}^{c}=M^{c}\left(V_{t}^{c}, s c_{t} U_{t}^{h}+s o_{t} N_{t}^{s h}\right) \quad \text { and } \quad M_{t}^{s}=M^{s}\left(V_{t}^{s}, s s_{t} U_{t}^{h}+U_{t}^{l}\right)
$$

where $s c_{t}, s s_{t}$ and $s o_{t}$ represent search efficiencies; the search efficiency of the low-skilled worker on the simple job market is normalized to one. Both matching functions are assumed to be linear homogeneous.

The probabilities of finding a complex or a simple job per unit of search intensity can be respectively written as follows:

$$
p_{t}^{c}=\frac{M_{t}^{c}}{s c_{t} U_{t}^{h}+s o_{t} N_{t}^{s h}} \quad \text { and } \quad p_{t}^{s}=\frac{M_{t}^{s}}{s s_{t} U_{t}^{h}+U_{t}^{l}} .
$$

preference between the two types of workers (the firm surplus depends on the worker), it never turns down an application as long as the asset value of the job is positive.

${ }^{8}$ This seems a realistic assumption. For instance Forgeot and Gautié (1997) show, on French data, that overqualification leads to a lower employment duration and a higher mobility on the labour market. 


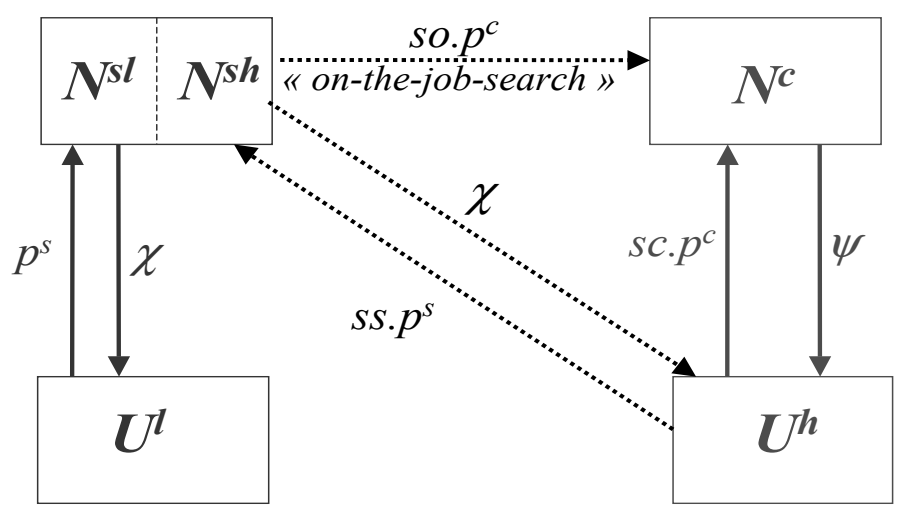

Figure 1: Labour market flows and transition probabilities

The probabilities of filling a complex and a simple job vacancy are similarly given by:

$$
q_{t}^{c}=\frac{M_{t}^{c}}{V_{t}^{c}} \quad \text { and } \quad q_{t}^{s}=\frac{M_{t}^{s}}{V_{t}^{s}} .
$$

The probability that a simple job is filled is the sum of the probabilities of hiring a high-skilled worker and a low-skilled worker:

$$
q_{t}^{s h}=\frac{s s_{t} U_{t}^{h}}{s s_{t} U_{t}^{h}+U_{t}^{l}} q_{t}^{s} \quad \text { and } \quad q_{t}^{s l}=\frac{U_{t}^{l}}{s s_{t} U_{t}^{h}+U_{t}^{l}} q_{t}^{s} .
$$

Finally, we assume two exogenous job destruction rates $\psi$ (for the complex jobs) and $\chi$ (for the simple jobs), implying for each type of job and worker the following employment dynamics (in terms of vacancies and job-seekers' search effort respectively):

$$
\begin{aligned}
N_{t+1}^{c}= & (1-\psi) N_{t}^{c}+q_{t}^{c} V_{t}^{c}, \\
= & (1-\psi) N_{t}^{c}+p_{t}^{c}\left[s c_{t} U_{t}^{h}+s o_{t} N_{t}^{s h}\right] . \\
N_{t+1}^{s h}= & \left(1-\chi-s o_{t} p_{t}^{c}\right) N_{t}^{s h}+q_{t}^{s h} V_{t}^{s}, \\
= & \left(1-\chi-s o_{t} p_{t}^{c}\right) N_{t}^{s h}+p_{t}^{s} s s_{t} U_{t}^{h} . \\
N_{t+1}^{s l}= & (1-\chi) N_{t}^{s l}+q_{t}^{s l} V_{t}^{s}, \\
& =(1-\chi) N_{t}^{s l}+p_{t}^{s} U_{t}^{l} .
\end{aligned}
$$

Figure 1 summarizes these labour market flows and transition probabilities. Armed with these definitions and notations, we can now describe firm and household behaviour. 


\subsection{The Intermediate Good Firms}

We distinguish "high-tech" or "low-tech" intermediate good firms. All are assumed to be single job firms. High-tech (resp. low-tech) firms offer complex (resp. simple) jobs.

The asset values of a complex vacancy and of a filled complex job will be denoted $W^{V C}$ and $W^{F C}$ respectively. Given the transition probabilities defined in the previous subsection, these values are determined by:

$$
\begin{aligned}
& W_{t}^{V C}=-a+\tilde{\beta}_{t} \mathrm{E}_{t}\left[q_{t}^{c} W_{t+1}^{F C}+\left(1-q_{t}^{c}\right) W_{t+1}^{V C}\right], \\
& W_{t}^{F C}=c_{t}^{c} y^{c}-w_{t}^{c}+\tilde{\beta}_{t} \mathrm{E}_{t}\left[(1-\psi) W_{t+1}^{F C}+\psi W_{t+1}^{V C}\right],
\end{aligned}
$$

where $a$ denotes the cost of keeping the complex vacancy open, $\tilde{\beta}_{t}$ is the rate at which firms discount future profits, while $c_{t}^{c}$ stands for the market price of a complex (high-tech) good and $w_{t}^{c}$ is the wage paid to the high-skilled worker. The productivity of the latter is equal to $y^{c}$.

Asset values for simple vacancies and jobs take more complicated forms because these positions may be held by low- or by high-skilled workers. Because of high-skilled workers' search behaviour, high- and low-skilled workers have different hiring and exit probabilities. They also have different productivity levels. The productivity of a high-skilled worker on a simple job is $y^{s}$; the productivity of a low-skilled worker is assumed to be a fraction $\nu$ of the latter. Let $W^{V S}$ denote the asset value of a simple vacancy, while $W^{F S H}$ and $W^{F S L}$ denote the asset values of a filled simple job held respectively by a high-skilled and a low-skilled worker. These asset values are determined by the following dynamic equations:

$$
\begin{aligned}
W_{t}^{V S} & =-b+\tilde{\beta}_{t} \mathrm{E}_{t}\left[q_{t}^{s h} W_{t+1}^{F S H}+q_{t}^{s l} W_{t+1}^{F S L}+\left(1-q_{t}^{s h}-q_{t}^{s l}\right) W_{t+1}^{V S}\right], \\
W_{t}^{F S H} & =c_{t}^{s} y^{s}-w_{t}^{s h}+\tilde{\beta}_{t} \mathrm{E}_{t}\left[\left(1-\chi-p_{t}^{c} s o_{t}\right) W_{t+1}^{F S H}+\left(\chi+p_{t}^{c} s o_{t}\right) W_{t+1}^{V S}\right], \\
W_{t}^{F S L} & =\nu c_{t}^{s} y^{s}-w_{t}^{s l}+\tilde{\beta}_{t} \mathrm{E}_{t}\left[(1-\chi) W_{t+1}^{F S L}+\chi W_{t+1}^{V S}\right],
\end{aligned}
$$

where $b$ denotes the cost of keeping the simple vacancy open, while $c_{t}^{s}$ stands for the market price of a simple (low-tech) goods. The wages paid by low-tech firms to high- or low-skilled workers are denoted $w_{t}^{s h}$ and $w_{t}^{s l}$ respectively. It is worth pointing out that whether the value of a simple job is higher or lower if filled with a skilled worker is a priori ambiguous. It depends on the expected duration of the match, the relative wages and the relative productivity. The expected duration of the match is lower with a high-skilled worker (he may leave for a complex job), whereas the relative productivity $\nu$ of a low-skilled worker is a matter of calibration and can be lower or higher than 1 (in other words, a low-skilled could be less or more productive than a high-skilled on a simple 
job).

Finally, the number of high- or low-tech firms is determined by the usual free entry conditions $\left(W_{t}^{V C}=W_{t}^{V S}=0\right)^{9}$.

\subsection{The Representative Final Good Firm}

We assume a representative final good firm. Producing the final good $y_{t}$ requires three types of inputs: capital $K_{t}$, high-tech (complex) intermediate good $Q_{t}^{c}$, low-tech (simple) intermediate goods $Q_{t}^{s}$. The demand for these three inputs is determined by profit maximization:

$$
\max _{K_{t+1}, Q_{t}^{c}, Q_{t}^{s}} F\left(K_{t}, Q_{t}^{c}, Q_{t}^{s}\right)-c_{t}^{c} Q_{t}^{c}-c_{t}^{s} Q_{t}^{s}-\left(r_{t}+\delta\right) K_{t},
$$

where $F($.$) is a linear homogeneous production function, r_{t}$ is the net interest rate paid to capital owners and $\delta$ an exogenous capital depreciation rate. The first-order optimality conditions can then be written as follows:

$$
F_{K_{t}}=r_{t}+\delta ; \quad F_{Q_{t}^{c}}=c_{t}^{c} ; \quad F_{Q_{t}^{s}}=c_{t}^{s} .
$$

where $F_{X_{t}}$ is the first-partial derivative of $F($.$) with respect to X_{t}$. Because the intermediate good prices $c_{t}^{c}$ and $c_{t}^{s}$ are market-clearing prices, we also have:

$$
Q_{t}^{c}=y^{c} N_{t}^{c} ; \quad Q_{t}^{s}=y^{s}\left(N_{t}^{s h}+\nu N_{t}^{s l}\right)
$$

\subsection{The Representative Household}

Let the representative household's value function be represented by the following function of the household's four state variables:

$$
W_{t}^{H}=W^{H}\left(K_{t+1}, N_{t}^{c}, N_{t}^{s h}, N_{t}^{s l}\right) .
$$

All members of the household inelastically supply one unit of labour. The decision variables of the household are the consumption level $C_{t}$ and the search effort of job seekers. We assume that low-skilled unemployed workers devote all their time searching on the simple job market. Their search efficiency is normalized to one. High-skilled unemployed workers allocate their total search time (normalized to one) between the simple and the complex job markets. Their search efficiency on the complex (resp. simple) job market, denoted $s c_{t}$ (resp. $s s_{t}$ ), is an increasing and concave function of the search time devoted to that market (eut and $\left(1-e u_{t}\right)$ respectively). High-skilled

\footnotetext{
${ }^{9}$ Since $W_{t}^{V S}=0$ in equilibrium, a simple firm will always accept a low-skilled as long as $W_{t}^{F S L}>0$, and a simple firm will always accept a high-skilled as long as $W_{t}^{F S H}>0$ (as it is within our calibration, see section 3.1).
} 
workers employed on a simple job may spend a fraction $e o_{t}$ of their leisure time searching for a better paid complex job. Their on-the-job search efficiency $s o_{t}$ is an increasing concave function of $e o_{t}$. There is an on-the-job search disutility but no disutility of search for unemployed agents ${ }^{10}$.

With these definitions and notations, the household optimization programme can be written in the form of the following Bellmann equation:

$$
W_{t}^{H}=\max _{C_{t}, e u_{t}, e o_{t}}\left\{\mathcal{U}\left(C_{t}\right)-\mathcal{D}\left(e o_{t}\right) N_{t}^{s h}+\beta \mathrm{E}_{t}\left[W_{t+1}^{H}\right]\right\},
$$

$\mathcal{U}($.$) is an increasing and concave utility function, \mathcal{D}($.$) is an increasing and convex disutility$ function, $\beta$ is a subjective discount factor. The optimization is subject to constraints (1), (7), (9), (11) and to the flow budget constraint (income $=$ expenditure):

$$
w_{t}^{c} N_{t}^{c}+w_{t}^{s h} N_{t}^{s h}+w_{t}^{s l} N_{t}^{s l}+w_{t}^{u}\left(U_{t}^{h}+U_{t}^{l}\right)+\left(r_{t}+\delta\right) K_{t}+\Pi_{t}=K_{t+1}-(1-\delta) K_{t}+C_{t}+T_{t},
$$

where $w_{t}^{u}$ stands for the benefits received by an unemployed worker, $\Pi_{t}$ stands for the profits (value-added net of labour and vacancy costs) redistributed by intermediate good firms and $T_{t}$ stands for the (lump sum) taxes levied to finance the unemployment benefits. The first-order optimality conditions can then be written as follows:

$$
\begin{aligned}
\mathcal{U}_{C_{t}} & =\beta \mathrm{E}_{t}\left[\left(1+r_{t+1}\right) \mathcal{U}_{C_{t+1}}\right], \\
\mathrm{E}_{t}\left[p_{t}^{c} s c_{e u_{t}} W_{N_{t+1}^{c}}^{H}\right] & =\mathrm{E}_{t}\left[p_{t}^{s} s s_{1-e u_{t}} W_{N_{t+1}^{s h}}^{H}\right] \\
\mathcal{D}_{e o_{t}} & =\beta p_{t}^{c} s o_{e o t} \mathrm{E}_{t}\left[W_{N_{t+1}^{c}}^{H}-W_{N_{t+1}^{s h}}^{H}\right] .
\end{aligned}
$$

Equation (23) characterizes the optimal intertemporal consumption path. Note that partial derivatives are denoted by using subscript. For instance, the marginal utility of consumption is denoted by $\mathcal{U}_{C_{t}}$. Equivalently, in equation (24), we denote by $s c_{e u_{t}}$ the effect on search efficiency of marginally increasing the fraction $e u_{t}$ of time devoted to the search of a complex job. We similarly define $s s_{1-e u_{t}}$, with $1-e u_{t}$ representing the fraction of time devoted to the simple job market. The left hand side of equation (24) represents the expected utility gain associated to an increase in search effort on the complex job market, whereas the right hand side represents the expected utility gain associated to an increase in search effort on the simple job market. The optimum allocation of search intensity $e u_{t}$ is such that the two expected marginal gains are equal. The left hand side of equation (25) represents the marginal disutility of on-the-job search whereas the right hand side

\footnotetext{
${ }^{10}$ On-the-job disutility is necessary to get endogenous on-the-job search (if not, working agents would search full time). Disutility of search for unemployed is not necessary, unless we allow for endogenous participation rate (which is not the case in this model: all agents participate in the labour market).
} 
represents the expected utility gain of marginally increasing on-the-job search.

From the envelope theorem, we obtain the following additional dynamic relationships:

$$
\begin{aligned}
W_{N_{t}^{c}}^{H}= & \mathcal{U}_{C_{t}}\left(w_{t}^{c}-w_{t}^{u}\right)+\beta\left(1-\psi-s c_{t} p_{t}^{c}\right) \mathrm{E}_{t}\left[W_{N_{t+1}^{c}}^{H}\right]-\beta s s_{t} p_{t}^{s} \mathrm{E}_{t}\left[W_{N_{t+1}^{s h}}^{H}\right], \\
W_{N_{t}^{s h}}^{H}= & \mathcal{U}_{C_{t}}\left(w_{t}^{s h}-w_{t}^{u}\right)-\mathcal{D}\left(e o_{t}\right)+\beta\left(s o_{t}-s c_{t}\right) p_{t}^{c} \mathrm{E}_{t}\left[W_{N_{t+1}^{c}}^{H}\right] \\
& +\beta\left(1-\chi-s o_{t} p_{t}^{c}-s s_{t} p_{t}^{s}\right) \mathrm{E}_{t}\left[W_{N_{t+1}^{s h}}^{H}\right] \\
W_{N_{t}^{s l}}^{H}= & \mathcal{U}_{C_{t}}\left(w_{t}^{s l}-w_{t}^{u}\right)+\beta\left(1-\chi-p_{t}^{s}\right) \mathrm{E}_{t}\left[W_{N_{t+1}^{s l}}^{H}\right]
\end{aligned}
$$

These equations represent the households marginal value functions and are equivalent to equations (13), (15) and (16) in the firm's section.

Finally, firms are owned by household and the rate at which future profits should be discounted is given by:

$$
\tilde{\beta}_{t}=\beta \mathrm{E}_{t}\left[\frac{\mathcal{U}_{C_{t+1}}}{\mathcal{U}_{C_{t}}}\right]
$$

\subsection{Wage Determination}

The relative wage of low-skilled workers has in many countries remained remarkably stable over the last decades ${ }^{11}$. In a context of increased relative demand for skilled workers and increased low skilled unemployment, this relative wage stability may look strange. It can be related though to so-called 'envy effects', which make workers of a given skill group sensitive to the wage received by workers of the other group ${ }^{12}$. For instance, trade union preferences may be such that they want average productivity growth to be beneficial to all workers, including low-skilled ones, even though relative demand changes may imply more low-skilled unemployment as a result. This scenario is particularly relevant in countries with generous unemployment benefit schemes and significant union power. The stability of relative wages may be obtained through minimum wage regulations or other wage bargaining institutions, with e.g. some sectors or unions playing the role of "leader".

Our objective in this paper is to evaluate the extent to which relative wage rigidities may contribute to explain the rise of the low-skilled unemployment rate. We thus compare the quantitative implications of two alternative specifications, with and without relative wage rigidities. We want

\footnotetext{
${ }^{11}$ In OECD (1996), the distribution of earnings (D9/D5 (ratio of the upper earnings limit of the ninth decile of workers to the upper limit of the fifth decile) and D5/D1) are provided for eleven EU countries. For all these countries (except the UK), these ratios remain fairly stable from 1979 to 1995, see Appendix 1 . See also OECD (2003) for a similar conclusion.

${ }^{12}$ Similar envy effects may be at work for regional or sectoral wages. See for instance de la Croix (1994) for a discussion of the consequences of envy effects in a setup with group specific trade unions.
} 
to introduce the rigidity in the simplest possible manner and to focus on its implications across markets, including job competition and de-skilling effects. The rigid relative wage specification thus assumes that the wage $w_{t}^{s}$ paid on simple jobs is a constant fraction of the wage $w_{t}^{c}$ paid on complex job:

$$
w_{t}^{s}=\gamma w_{t}^{c}
$$

where the complex wage $w_{t}^{c}$ is determined by Nash bargaining. The value of parameter $\gamma$ (the rigid relative wage) is meant to represent the outcome from centralized labour market regulations and institutions. We further assume that high- and low-skilled workers on simple jobs (in a context with job competition and deskilling) are paid the same wage , i.e.,

$$
w_{t}^{s h}=w_{t}^{s l}=w_{t}^{s}
$$

The complex wage $w_{t}^{c}$ is renegotiated in every period with the intermediate good firm. The bargained wage is determined by the maximization of the Nash product (see for instance Pissarides (2000)):

$$
\max _{w_{t}^{c}}\left(\frac{W_{N_{t}^{c}}^{H}}{\mathcal{U}_{C_{t}}}\right)^{\eta^{c}}\left(W_{t}^{F C}-W_{t}^{V C}\right)^{\left(1-\eta^{c}\right)},
$$

where $\eta^{c}$ represents the bargaining power of high-skilled worker ${ }^{13}$. Using the free entry condition, the first order condition gives:

$$
W_{N_{t}^{c}}^{H}=\eta^{c}\left(W_{N_{t}^{c}}^{H}+\mathcal{U}_{C_{t}} W_{t}^{F C}\right)
$$

A similar approach is used for the determination of the bargained simple wages $\left(w_{t}^{s h}\right.$ and $\left.w_{t}^{s l}\right)$ in the flexible relative wage model (see subsection 3.2 .2 below).

Finally, the unemployment benefit $w_{t}^{u}$ is assumed to be the same for all workers and indexed to the average wage:

$$
w_{t}^{u}=w^{u} \frac{N_{t}^{c} w_{t}^{c}+N_{t}^{s h} w_{t}^{s h}+N_{t}^{s l} w_{t}^{s l}}{N_{t}^{c}+N_{t}^{s h}+N_{t}^{s l}}
$$

where $w^{u}$ is the replacement ratio.

\footnotetext{
${ }^{13}$ We do not make any distinction between a bargain with an unemployed and an overeducated worker. In both cases, the threat point is unemployment. This assumption is quite standard in on-the-job-search literature and allows to keep a unique complex wage. The household's surplus is in utility term while the firm surplus is in monetary term. To have the same units, we divide the household's surplus by the utility. See for instance Merz (1995) for a similar equation.
} 


\subsection{Equilibrium}

The maximization programs for both the representative firm (equation (17)) and the representative household (equation (21)) are strictly concave. Moreover, consumption is allocated independently of employment status (utility of consumption additively separable). Therefore, the existence of a unique equilibrium satisfying equations (17) and (21) can be easily demonstrated using the contraction mapping theorem (see for instance Ljungqvist and Sargent (2000)).

Given initial conditions $K_{0}, N_{0}^{s l}, N_{0}^{s h}$ and $N_{0}^{c}$, an equilibrium is a vector of prices $\left\{\mathcal{P}_{t}\right\}_{t=0}^{\infty}=$ $\left\{w_{t}^{s l}, w_{t}^{s h}, w_{t}^{c}, r_{t}, c_{t}^{s}, c_{t}^{c}\right\}_{t=0}^{\infty}$ and a vector of quantities $\left\{\mathcal{Q}_{t}\right\}_{t=0}^{\infty}=\left\{\left\{\mathcal{Q}_{t}^{F}\right\}_{t=0}^{\infty},\left\{\mathcal{Q}_{t}^{H}\right\}_{t=0}^{\infty},\left\{\mathcal{Q}_{t}^{R}\right\}_{t=0}^{\infty}\right\}$, with $\left\{\mathcal{Q}_{t}^{F}\right\}_{t=0}^{\infty}=\left\{V_{t}^{s}, V_{t}^{c}\right\}_{t=0}^{\infty},\left\{\mathcal{Q}_{t}^{H}\right\}_{t=0}^{\infty}=\left\{C_{t}, e u_{t}, e o_{t}\right\}_{t=0}^{\infty}$ and $\left\{\mathcal{Q}_{t}^{R}\right\}_{t=0}^{\infty}=\left\{Q_{t}^{s}, Q_{t}^{c}, K_{t+1}\right\}_{t=0}^{\infty}$, such that:

- given a vector of prices $\left\{\mathcal{P}_{t}\right\}_{t=0}^{\infty},\left\{\mathcal{Q}_{t}^{F}\right\}_{t=0}^{\infty}$ is solution to the problem of the intermediate good firm (equations (12) and (14))

- given a vector of prices $\left\{\mathcal{P}_{t}\right\}_{t=0}^{\infty},\left\{\mathcal{Q}_{t}^{H}\right\}_{t=0}^{\infty}$ is solution to the household's problem (equations (23) to $(25))$

- given a vector of prices $\left\{\mathcal{P}_{t}\right\}_{t=0}^{\infty},\left\{\mathcal{Q}_{t}^{R}\right\}_{t=0}^{\infty}$ is solution to the problem of the final good firm (equation (18))

- given a vector of quantities $\left\{\mathcal{Q}_{t}\right\}_{t=0}^{\infty},\left\{\mathcal{P}_{t}\right\}_{t=0}^{\infty}$ clears the goods and the capital markets (equations (19) and (22))

- wages are set according to the wage determination mechanism (equations (32) and (30))

- lump sum taxes are such that the government budget constraint is at equilibrium every period: $T_{t}=w_{t}^{u}\left(U_{t}^{h}+U_{t}^{l}\right)$

\section{Model Calibration and Simulations}

In this section we calibrate the model and use deterministic simulation exercises to try to understand the rise in the European unemployment rate.

\subsection{Calibration}

We use the following specific functions:

$$
M_{t}^{s}=m_{0}^{s}\left(V_{t}^{s}\right)^{\lambda^{s}}\left(s s_{t} U_{t}^{h}+U_{t}^{l}\right)^{1-\lambda^{s}} \quad \text { matching simple jobs }
$$




$$
\begin{aligned}
M_{t}^{c} & =m_{0}^{c}\left(V_{t}^{c}\right)^{\lambda^{c}}\left(s c_{t} U_{t}^{h}+s o_{t} N_{t}^{s h}\right)^{1-\lambda^{c}} & & \text { matching complex jobs } \\
F_{t} & =e\left(K_{t}\right)^{\theta}\left(N_{t}^{c}\right)^{\mu}\left(N_{t}^{s h}+\nu N_{t}^{s l}\right)^{1-\theta-\mu} & & \text { production function } \\
\mathcal{U}_{t} & =\ln C_{t} & & \text { utility function } \\
\mathcal{D}_{t} & =\tau e o_{t} & & \text { disutility function } \\
s c_{t} & =\phi_{0}^{s c}+\phi_{1}^{s c} \sqrt{e u_{t}} & & \text { search efficiency (i) } \\
s s_{t} & =\phi_{0}^{s s}+\phi_{1}^{s s} \sqrt{1-e u_{t}} & & \text { search efficiency (ii) } \\
s o_{t} & =\phi_{0}^{s o}+\phi_{1}^{s o} \sqrt{e o_{t}} & & \text { search efficiency (iii) }
\end{aligned}
$$

The matching function on each job market (simple and complex) is represented by the usual Cobb-Douglas specification with constant-returns-to-scale.

The specification of the production function is crucial for the analysis of relative demand shifters like skill-biased technological change. Focusing on the relative demand for workers on simple and complex jobs in a CES framework, we obtain from standard cost minimization:

$$
\frac{N^{c}}{N^{s}}=\left\{\left(\frac{\mu}{1-\mu-\theta}\right)^{\sigma}\left(\frac{A^{s}}{A^{c}}\right)^{1-\sigma}\right\}\left\{\frac{w^{s}}{w^{c}}\right\}^{\sigma},
$$

where $\sigma$ stands for the elasticity of substitution between the two types of jobs. This formulation is similar to the one used by Katz and Murphy (1992) or Krusell, Ohanian, Rios-Rull, and Violante $(2000)^{14}$. We assume constant returns to scale. Parameters $A^{c}$ and $A^{s}$ measure (specific) laborsaving technical progress; parameters $\mu$ and $\theta$ correspond to the weights of complex jobs and of capital respectively in the production function. The first bracketed term on the right hand side is a relative demand shifter: a change in its value changes the relative demand for labor, at given relative wages. Estimates of the elasticity of substitution $\sigma$ reported in the literature vary a lot, depending among other things on the type of data and on the estimation methodology. Katz and Murphy (1992) obtain a value of 1.41 , but show that a value in the range $0.5-1.5$ is compatible with observed relative wage and employment changes. Manacorda and Petrongolo (1999) obtain $\sigma=1$ on aggregate OECD data; Sneessens and Shadman (2000) obtain a similar result on Belgian data. We shall thus assume $\sigma=1$ and use the Cobb-Douglas production function mentioned above. The relative demand shift is thus given by the change in the value of parameter $\mu$. A larger value of $\mu$

\footnotetext{
${ }^{14}$ Krusell et al. (2000) actually use a more sophisticated representation of the production technology, with two types of capital (equipment and structures) and with complementarity between complex jobs and capital equipment. Because we focus on general rather than partial equilibrium, there is unfortunately no room in this paper for such a sophistication.
} 
increases the relative demand for workers on complex jobs.

We represent the instantaneous utility of consumption by the logarithm of consumption expenditures. The disutility of devoting leisure time to on-the-job search is assumed to be linear. We represent the relationship between search time and search efficiency by a concave function (more precisely, search efficiency is a linear function of the square root of search time).

The numerical values given to the parameters of these functions are reported in Table 1 . One period of time corresponds to one quarter. The psychological discount factor $(\beta)$ is set to 0.99 , implying a steady state real interest rate of 0.01 (real interest rate of $4 \%$ per annum). Parameter $\theta$ is the elasticity of output with respect to capital, and coincides with the capital share of total income. We set it at the standard value 0.33 . The depreciation rate $\delta$ is set to 0.025 and implies a steady state capital-output ratio of 9. Labour productivity $y^{c}$ and $y^{s}$ in the complex and simple intermediate goods firms are (without loss of generality) normalized to 1 . The relative productivity of a low-skilled worker on a simple job $(\nu)$ is set at 0.8 . This value is such that, although the lowskilled worker's productivity is large enough to generate a positive surplus, the intermediate goods firm prefers to fill a simple job vacancy with a high-skilled worker (more formally $\nu=0.8$ implies $\left.W^{F S H}>W^{F S L}>0\right)$. In other words, the higher productivity for the high-skilled more than compensates their higher quit probability. This particular choice has however little impact on the properties of the model. We assume that recruiting costs are higher for complex jobs $(a>b)$. Our calibration of $a$ and $b$ implies that total vacancy costs represent $3.7 \%$ of total labour costs, $2.5 \%$ of output.

Most of the remaining parameters are calibrated on Belgian data. The reference period is the second half of the nineties (mainly 1995-97), a period during which the Belgian economy was neither in a recession nor in a boom. The proportion $\alpha$ of high-skilled workers is defined as the proportion of workers with a education level equal to a upper-secondary degree or more. We set $\alpha$ and $\mu$ (the elasticity of output with respect to complex jobs) at values corresponding to the 1995-96 values obtained by Sneessens and Shadman (2000) for Belgium $(\alpha=0.67, \mu=0.51)$. The elasticity of job matches with respect to vacancies $(\lambda)$ is usually estimated to be in between 0.4 and 0.6. Using 1997 Belgian data, Van der Linden and Dor (2002) estimate it at 0.4 (without distinction between high- and low-skilled jobs) and we therefore follow them by setting $\lambda^{c}=\lambda^{s}=0.4$, for both complex and simple jobs.

The parameter determining the worker's share of a match surplus is usually set at the same value as the coefficient of unemployment in the matching function (see for instance Merz (1995) and 


\begin{tabular}{|c|c|c|c|}
\hline Symbol & Value & Symbol & Value \\
\hline \multicolumn{4}{|c|}{ Labour force composition } \\
\hline$\alpha$ & 0.67 & & \\
\hline \multicolumn{4}{|c|}{ Job destruction rates } \\
\hline$\psi$ & 0.025 & $\chi$ & 0.05 \\
\hline \multicolumn{4}{|c|}{ Matching functions } \\
\hline$m_{0}^{c}$ & 0.40 & $\lambda^{c}$ & 0.40 \\
\hline$m_{0}^{s}$ & 0.30 & $\lambda^{s}$ & 0.40 \\
\hline \multicolumn{4}{|c|}{ Production functions } \\
\hline$\theta$ & 0.33 & $\mu$ & 0.51 \\
\hline$e$ & 1.00 & $\nu$ & 0.80 \\
\hline$y^{c}$ & 1.00 & $y^{s}$ & 1.00 \\
\hline \multicolumn{4}{|c|}{ Instantaneous disutility of on-the-job search } \\
\hline$\tau$ & 0.41 & & \\
\hline \multicolumn{4}{|c|}{ Search efficiencies } \\
\hline$\phi_{0}^{s c}$ & 0.10 & $\phi_{1}^{s c}$ & 0.50 \\
\hline$\phi_{0}^{s s}$ & 0.40 & $\phi_{1}^{s s}$ & 1.00 \\
\hline$\phi_{0}^{s o}$ & 0.60 & $\phi_{1}^{s o}$ & 0.50 \\
\hline \multicolumn{4}{|c|}{ Vacancy costs } \\
\hline$a$ & 0.90 & $b$ & 0.26 \\
\hline \multicolumn{4}{|c|}{ Wage determination } \\
\hline$\eta^{c}$ & 0.60 & $\gamma$ & $2 / 3$ \\
\hline$w^{u}$ & 0.34 & & \\
\hline \multicolumn{4}{|c|}{ Subjective discount and capital depreciation } \\
\hline$\beta$ & 0.99 & $\delta$ & 0.025 \\
\hline
\end{tabular}

Table 1: Numerical parameter values 
Andolfatto (1996) $)^{15}$. We follow this practice in choosing the value of $\eta^{c}$ (the wage rule on the complex job market), although in our setup it will not imply that the decentralized economy yields a social optimum. As discussed in section 2.5, we assume that wages on the simple job market are a constant fraction of the complex wage. This corresponds to empirical observations: over the last decades, earnings dispersion remained stable in most European countries (see Figure 6 in Appendix 1). We fix this ratio of simple to complex wages $(\gamma)$ at $2 / 3$. This value coincides with the relative mean gross wage of the $33 \%$ lowest-paid workers in Belgium (see ONSS (2000)). This ratio is moreover similar in most European countries: the OECD (1996) shows that the D1/D5 ratio (rough approximation of $\gamma$ ) is respectively of 0.70, 0.70, 0.61 and 0.64 in Belgium, Germany, France and The Netherlands. The value of the average replacement ratio $w^{u}$ is set at 0.34 , the value estimated by Van der Linden and Dor (2002) for Belgium in 1997. The same authors estimate a lower bound for the job destruction rate (or transition rate from employment to unemployment) equal to 0.013 (monthly data). Simple jobs being typically more precarious than complex jobs, we impose the complex jobs destruction rate $\psi$ to be lower than the simple jobs destruction rate $\chi$. Using the Van der Linden and Dor (2002) lower-bound estimate as a reference, we set the complex and simple job destruction rates at $\psi=0.025$ and $\chi=0.05$ respectively (quarterly data).

For simplicity, we want to normalize to 1 the three slope parameters in the search efficiency functions $\left(\phi_{1}^{s c}=\phi_{1}^{s s}=\phi_{1}^{s o}=1\right)$. However, this gives a too high elasticity of search efficiency to shocks (more precisely, the sensitivity of $s c_{t}$ and $s o_{t}$ to the tightness of the complex job market is too high) which can lead to negative values for $W_{N_{t}^{c}}^{H}$ and $W_{N_{t}^{s h}}^{H}$ (see equations (26) and (27)). To solve this problem, $\phi_{1}^{s c}$ and $\phi_{1}^{s o}$ are reduced to 0.5 . We still have to fix the following six parameters: the two matching efficiencies $m_{o}^{c}$ and $m_{o}^{s}$, the three independent parameters of the search efficiency functions $\left(\phi_{0}^{x}, x \epsilon\{s c, s s, s o\}\right)$ and the disutility parameter $\tau$. We choose their values so as to satisfy the following six steady state conditions: low- and high-skilled unemployment rates around 0.20 and 0.07 respectively (values obtained from Sneessens and Shadman (2000) for Belgium, updated for 1995-96); probabilities of finding a complex job and a simple job equal to $p^{c}=0.40$ and $p^{s}=0.20$ respectively (estimates based on Cockx and Dejemeppe (2002) for the early nineties) ${ }^{16}$; and equal probabilities (around 0.50) to fill complex or simple vacancies ( $q^{c}$ and $q^{s}$ respectively). These latter values are based on Delmotte, Van Hootegem, and Dejonckheere (2001). They report

\footnotetext{
${ }^{15}$ Their motivation is the so-called Hosios (1990) condition: in models like Merz's or Andolfatto's, this sharing rule implies that the decentralized economy gives the same outcomes as the social planner problem.

${ }^{16}$ The probability that a worker finds a job during the first three months of unemployment is estimated at 0.64 for a worker with post-secondary education, 0.39 with upper secondary education, 0.30 with lower secondary education and 0.28 with primary education or no education. The values kept for $p^{c}$ and $p^{s}$ take into account both our definition of the two skill groups and the fact that first quarter exit probabilities should be regarded as upper bounds.
} 
that in 2000, $52 \%$ of the total vacancies were easily filled (within 3 months), $25 \%$ were filled with difficulty (vacancies open more than 3 months) and $33 \%$ were never filled. Carefully examining which types of jobs are most easily filled does not suggest any difference between complex jobs and simple jobs.

A result of this calibration exercise is that $e u \cong 0.80$ and $e o \cong 0.10$. In other words, skilled unemployed spend $80 \%$ of their time searching for a complex job and $20 \%$ searching for a simple job. Moreover, the overeducated employed worker spends much less time searching than the unemployed. It also implies that the marginal efficiency of search for the skilled unemployed is higher for a simple job than for a complex job, that is $\partial s c / \partial e u<\partial s s / \partial(1-e u)$. Although it is difficult to find real data to justify these values/relationships, they seem intuitive (preference for skilled jobs, low on-the-job search and higher efficiency when searching for a simple job). Another result is that the proportion of high-skilled workers on simple jobs is around $8 \%$ (this is a measure of "job competition" or "crowding-out"). Delmotte, Van Hootegem, and Dejonckheere (2001) use survey questionnaires with business firms to compare the skill requirements of job vacancies and the skill characteristics of the workers who filled these vacancies. A worker is considered to be overeducated when his education level is above that demanded by the firm when opening the vacancy. According to these authors, $24 \%$ of all hired workers were overeducated in 2000. This figure may however overestimate the true number of overeducated workers. For instance, the education level indicated by a firm when opening a vacancy may only represent a lower bound rather than a strict requirement. Moreover distinguishing only two skill categories (rather than three or more) will mechanically and maybe drastically reduce the number of "overeducated" workers.

\subsection{Explaining the Rise in Low-skilled Unemployment}

As mentioned before, our model has been calibrated to Belgian data to reproduce the situation observed in 1996. Our objective in this section is to assess how far the rise in low-skilled unemployment observed after 1975 can be explained by changes in relative labour demand and supply. We thus recalculate the equilibrium values of the unemployment rates and the other endogenous variables obtained by changing only two parameters, the proportion of high-skilled workers $\alpha$ and the productivity coefficient of complex intermediate goods $\mu$. We compare stationary state equilibrium values and discuss the main features of the model ${ }^{17}$.

\footnotetext{
${ }^{17}$ Given the model complexity, it is difficult to analytically derive comparative statistics so only numerical results are provided. It is worth noting that all these results are quite robust to reasonable changes in our calibration.
} 


\begin{tabular}{|c|c|c|c|c|c|c|c|}
\hline & $\alpha$ & $\mu$ & NSB & $U^{h} / \alpha$ & $U^{l} /(1-\alpha)$ & $w^{s} / w^{c}$ & $\begin{array}{c}\text { crowding } \\
\text { out }\end{array}$ \\
\hline \multicolumn{8}{|c|}{ Actual data } \\
\hline 1977 & 0.22 & 0.18 & 1.31 & $4.7 \%$ & $6.8 \%$ & $67 \%$ & n.a. \\
\hline 1996 & 0.67 & 0.51 & 1.59 & $6.8 \%$ & $20.1 \%$ & $67 \%$ & n.a. \\
\hline $1977-96$ & +0.45 & +0.33 & +0.28 & +2.1 & +13.3 & +0.0 & $>0$ \\
\hline \multicolumn{8}{|c|}{ Model with rigid relative wages and endogenous crowding-out } \\
\hline 1977-96 & +0.45 & +0.33 & +0.28 & +2.7 & +10.1 & +0.0 & +6.4 \\
\hline \multicolumn{8}{|c|}{ Model with flexible relative wages and endogenous crowding-out } \\
\hline $1977-96$ & +0.45 & +0.33 & +0.28 & +1.0 & +2.3 & -11.3 & +7.7 \\
\hline \multicolumn{8}{|c|}{ Model with rigid relative wages and fixed crowding-out } \\
\hline $1977-96$ & +0.45 & +0.33 & +0.28 & +4.5 & +5.0 & +0.0 & +0.0 \\
\hline
\end{tabular}

Table 2: Skill bias, unemployment and relative wages: comparing actual and simulated data

\subsubsection{Comparative statics}

Table 2 reproduces the 1977 and 1996 values of $\alpha, \mu$, as well as the change observed over this period. These values are taken from Sneessens and Shadman (2000). The measure of the change in $\alpha$ is based on labor force statistics; the measure of the change in $\mu$ is based on the estimation of a Cobb-Douglas production function with three inputs (two types of labour and capital). The net skill bias (NSB in Table 2) is a measure of the net relative demand change. It is defined as the ratio of the relative productivity coefficient $(\mu /(1-\mu-\theta))$ and the relative labour force $(\alpha /(1-\alpha))$ of high- and low-skilled workers. In a simple model without vacancy costs and job competition, the difference between the low- and the high-skilled equilibrium unemployment rates would remain unchanged as long as NSB is unchanged; a positive change in NSB increases the difference between the two equilibrium unemployment rates if the relative wage is rigid ${ }^{18}$. From 1977 to 1996, the observed net skill bias increased by twenty-eight percentage points.

Table 2 (see the "Actual data" lines) also reproduces the observed values of the endogenous variables of interest: high- and low-skilled unemployment rates, relative wage $\left(w^{s} / w^{c}\right.$, where $w^{s}$ is the average simple wage) and crowding-out. From 1977 to 1996, low-skilled unemployment rate

\footnotetext{
${ }^{18}$ In a Cobb-Douglas model without vacancy costs and job competition, the relative employment levels are determined by $\frac{\alpha-U^{h}}{1-\alpha-U^{l}}=\frac{\mu}{1-\mu-\theta} \frac{w^{s}}{w^{c}}$.
} 
has dramatically increased, while the increase has remained moderate for the high-skilled. At the same time, the ratio between low- and high-skilled wages has remained unchanged, while the proportion of simple jobs held by high-skilled has probably increased. These values and observations are respectively taken from Sneessens and Shadman (2000), ONSS (2000) and Hartog (2000).

We see that our simulated model (see the "Model with rigid relative wages and endogenous crowding-out" line) reproduces pretty well the changes observed over the period 1977-96: the high-skilled unemployment rate increases moderately $(+2.7$ percentage points in the simulation, +2.1 in the data), while the low-skilled unemployment rate rises strongly $(+10.1$ in the simulation, +13.3 in the data). In the simulation, the proportion of simple jobs held by high-skilled workers (crowding-out) increases from $1.8 \%$ to $8.3 \%(+6.4)$. This increase in job competition replicates what happened in European countries over the last decades (see for instance Hartog (2000)).

\subsubsection{Alternative scenarios}

The model is very rich and has many different features. In this section, we test the sensitivity of our results to alternative modeling choices and we emphasize the crucial ingredients to obtain the quantitative results. This suggests that both wage rigidities and job competition are necessary for the results and therefore may have contributed substantially to the rise of low-skilled unemployment.

\section{Wage rigidities}

In order to better evaluate the implications of relative wage rigidities, we contrast the results obtained under the rigid relative wage assumption to those obtained under an assumption of individual wage bargaining similar to that taking place for complex jobs. More formally, the wage $w_{t}^{s l}$ (resp. $w_{t}^{s h}$ ) paid to a low-skilled (resp. high-skilled) worker employed on a simple job is determined by the maximization of the Nash product:

$$
\begin{aligned}
& \max _{w_{t}^{s l}}\left(\frac{W_{N_{t}^{s l}}^{H}}{\mathcal{U}_{C_{t}}}\right)^{\eta^{s l}}\left(W_{t}^{F S L}-W_{t}^{V S}\right)^{\left(1-\eta^{s l}\right)}, \\
& \max _{w_{t}^{s h}}\left(\frac{W_{N_{t}^{s h}}^{H}}{\mathcal{U}_{C_{t}}}\right)^{\eta^{s h}}\left(W_{t}^{F S H}-W_{t}^{V S}\right)^{\left(1-\eta^{s h}\right)},
\end{aligned}
$$

where $\eta^{s l}$ and $\eta^{s h}$ represent the worker's bargaining power (respectively for the low-skilled and the high-skilled). These parameters are set at values such that the initial steady state values are similar in both modeling strategies. This implies $\eta^{s l}=0.40$ and $\eta^{s h}=0.48$.

Table 2 reproduces the simulation results obtained with flexible relative wages (see the "Model 
with flexible relative wages and endogenous crowding-out" line). The increase in the low-skilled unemployment rate now remains moderate $(+2.3$ percentage points $)$, but requires a 11.3 percentage points decrease in the relative wage of low-skilled workers $\left(w^{s} / w^{c}\right)$. These two results are at odd with data and mean that wage rigidities are crucial to generate the results. There is also a slight increase in the high-skilled unemployment rate and a substantial increase in crowding-out. This increased crowding-out may seem strange given the decrease (in both absolute and relative terms) observed in the wage paid on simple jobs. Two effects are at work: the lower wage makes the simple job less attractive, but at the same time it increases the number of jobs and the probability of being hired.

\section{Crowding-out}

Repeating the same simulation experiment but this time eliminating the possibility of endogenous job competition (see the "Model with rigid relative wages and fixed crowding-out" line) shows that the change in low-skilled unemployment induced by the net skill bias change is only equal to 5 percentage points, compared to 10 in the model with job competition, whereas the increase in the high-skilled unemployment rate is too pronounced $^{19}$. The possibility of de-qualification is therefore crucial to explain the worsening of the low-skilled unemployment rate and the only slight increase in the high-skilled unemployment rate.

\section{General equilibrium modelisation and capital accumulation}

In the standard Mortensen-Pissarides one-job-one firm representation, skilled and unskilled labour are perfect substitutes and the two job markets are independent. Here, we instead assume a more realistic elasticity of substitution (elasticity equal to one rather than infinity), which allows for interactions between markets: a higher demand for one type of labour mechanically increases the marginal productivity of the other type of labour and hence its demand. As a result, the effects of shocks are magnified. In fact, we develop in this paper a general equilibrium modelisation, which means that we have interactions between all markets. For instance, capital stock is also included in the production function and its variation is endogenous. A NSB shock increases the capital stock by $12 \%$, which in turn reinforces the effects on employment. In a setup without these interactions, both unemployment rates would have increased slightly more after the same NSB shock. It is however worth pointing out that the general equilibrium modelisation is less important for our

\footnotetext{
${ }^{19}$ To conduct this simulation, we fix the proportion of high-skilled workers on simple jobs. As a result, the crowding-out does not move during the simulation. Alternatively, we could assume a perfectly segmented labour market (crowding-out fixed and equal to 0), but this would be a different model requiring a different calibration, and making any comparison with the initial model spurious.
} 
quantitative results than are wage rigidities and crowding-out.

\section{Conclusion}

Our objective in this paper was to examine the impact of biased technological change and shifts in labour force composition on the unemployment rate of low- and high-skill workers. For that purpose we constructed a dynamic general equilibrium model with two types of jobs and two types of workers, and with endogenous job competition and crowding-out effects. The model was calibrated on Belgian data (a country which in terms of wage and unemployment changes is quite representative of the EU average) and simulated to evaluate the quantitative importance over the last decades of the interactions between net skill bias effects and wage rigidities. Let us emphasize the following three results:

- our numerical simulations suggest that in the presence of relative wage rigidity, most of the unemployment rate changes observed between the late seventies and the mid nineties (moderate increase in high-skilled unemployment, huge increase the low skilled unemployment) can be explained by simply introducing two exogenous shocks, technological bias and labour force composition;

- search behaviour and job competition effects seem also to play a crucial role; our numerical simulations suggest that they may have considerably amplified the effects of the biased technological change on the low-skilled unemployment rate;

- the modeling of the production sector plays a crucial role; by distinguishing final and intermediate goods sectors, we avoid the assumption of perfect substitutability between lowand high-skilled labor implicit in many search equilibrium models and obtain a specification similar to the one traditionally used in real business cycle models.

Many questions have of course not been answered. For instance to explain rather than assume relative wage rigidity, or to endogenize the job destruction rate. Economic policy implications should also be investigated. We leave these questions for future research. 


\section{References}

Albrecht, J., And S. Vroman (2002): "A matching Model with Endogenous Skill Requirements," International Economic Review, 43, 283-305.

Andolfatto, D. (1996): "Business Cycles and Labor-Market Search," American Economic Review, 86(1), 112-132.

Autor, D., L. Katz, And A. Krueger (1998): "Computing Inequality: Have Computers Changed the Labor Market?," Quarterly Journal of Economics, 113(1169-1213).

Berman, E., J. Bound, And S. Machin (1998): "Implications of Skill-biased Technological Change: International Evidence," Quarterly Journal of Economics, 113, 1245-1279.

Bertola, G., F. Blau, and L. Kahn (2001): "Comparative Analysis of Labor Market Outcomes: Lessons for the US from International Long-run Evidence," NBER Working Paper 8526.

Blanchard, O., and J. Wolfers (2000): "The Role of Shocks and Institutions in the Rise of European Unemployment: the Aggregate Evidence," Economic Journal, 110, 1-33.

Buttler, F., And M. Tessaring (1993): "Human Kapital als Standortfaktor," Mitteilungen aus der Arbeitsmarkt- und Berufsforschung, 26(4), 465-476.

Cockx, B., And M. Dejemeppe (2002): "Do the Higher Educated Unemployed Crowd Out the Lower Educated Ones in a Competition for Jobs," IZA Discussion Paper 541.

DE LA Croix, D. (1994): "Wage Interdependence Through Decentralized Bargaining," Journal of Economic Surveys, 8(4), 371-403.

Delmotte, J., G. Van Hootegem, and J. Dejonckheere (2001): "Les Entreprises et le Recrutement en Belgique en 2000," Discussion paper, HIVA, Katholiek Universiteit Leuven.

Den HaAn, W., C. Haefke, and G. Ramey (2001): "Shocks and Institutions in a Job Matching Model," NBER Working Paper 8463.

Dolado, J., F. Felgueroso, and J. Jimeno (2000): "Youth Labor Markets in Spain: Education, Training and Crowding-out," European Economic Review, 44, 943-956.

Fonseca, R., B. Maillard, and H. Sneessens (1998): "Structural Adjustment and Unemployment Persistence: The Case of France and Spain," Robert Schuman Center discussion paper $98 / 47$. 
Forgeot, G., And J. Gautié (1997): "Chômage des Jeunes et Processus de Déclassement," Economie et Statistique, 304-305.

Gautier, P. (2002): "Unemployment and Search Externalities in a Model with Heterogeneous Jobs and Heterogeneous Workers," Economica, 69, 21-40.

Hartog, J. (2000): "Over-education and Earnings: Where Are We, Where Should We Go?," Economics of Education Review, 19, 131-147.

Hosios, A. (1990): "On the Efficiency of Matching and Related Models of Search and Unemployment," Review of Economic Studies, 57, 279-298.

Katz, L., And K. Murphy (1992): "Changes in Relative Wages, 1963-1987: Supply and Demand Factors," Quarterly Journal of Economics, 107(1), 35-78.

Krusell, P., L. Ohanian, J.-V. Rios-Rull, and G. Violante (2000): "Capital-Skill Complementarity and Inequality: A Macroeconomic Analysis," Econometrica, 68(5), 1029-1054.

Ljungqvist, L., and T. Sargent (2000): Recursive Macroeconomic Theory. The MIT Press.

— (2002): "The European Employment Experience," CEPR Discussion Paper 3543.

- (2004): "European Unemployment and Turbulence Revisited in a Matching Model," Journal of the European Economic Association, 2(2-3), 456-468.

Machin, S., and J. VAn Reenen (1998): "Technology and Changes in Skill Structure: Evidence from Seven OECD Countries," Quarterly Journal of Economics, 113, 1215-1244.

Manacorda, M., and B. Petrongolo (1999): "Skill Mismatch and Unemployment in OeCD Countries," Economica, 66, 181-207.

Merz, M. (1995): "Search in the Labor Market and the Real Business Cycle," Journal of Monetary Economics, 36, 269-300.

Mortensen, D., and C. Pissarides (1999): "Unemployment Responses to Skill-Biased Shocks: The Role of Labor Market Policy," The Economic Journal, 109(455), 242-265.

NickelL, S. (1997): "Unemployment and Labor Market Rigidities: Europe versus North America," Journal of Economic Perspectives, 11(3), 55-74.

OECD (1996): Employment Outlook. Paris. (2003): Employment Outlook. Paris. 
ONSS (2000): Rapport annuel. Bruxelles: Office National de sécurité Sociale.

Pissarides, C. (2000): Equilibrium Unemployment Theory. The MIT Press: Cambridge.

Sneessens, H., and F. Shadman (2000): "Analyse Macro-économique des Effets de Réductions Ciblées des Charges Sociales," Revue Belge de Sécurité Sociale, pp. 613-630.

VAn Der Linden, B., And E. Dor (2002): "Labor Market Policies and Equilibrium Employment: Theory and Application for Belgium," in Institutional and Financial Incentives for Social Insurance, ed. by C. d'Aspremont, V. Ginsburgh, H. Sneessens, and F. Spinnewyn. Kluwer Academic Publishers: Boston. 


\section{Appendix 1: Unemployment rates and wage rigidities: some facts}

As displayed in Figure 2, the unemployment rate in most European countries is around $2 \%$ at the end of the 50's. It then increases in the 70's, and remains high thereafter. It is currently around $8 \%$. In the US, the unemployment rate at the end of the 50's is around $4 \%$. It also increases during the 70 's but falls thereafter and is still currently around $4 \%$.

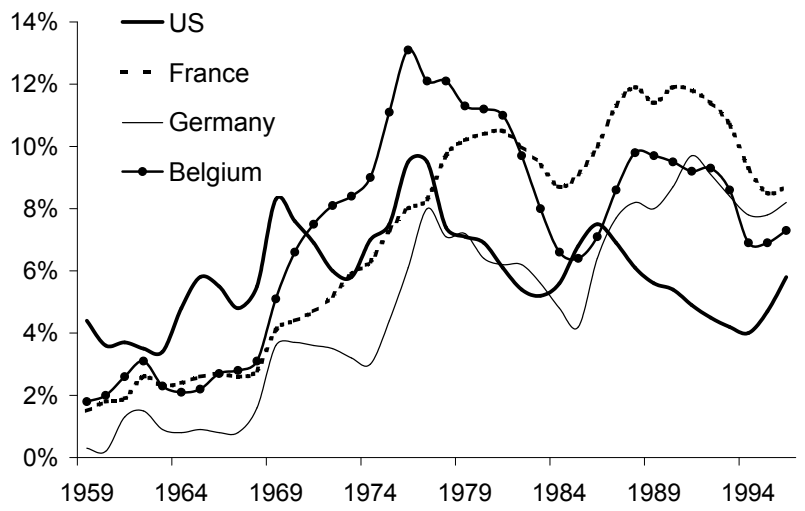

Source: OECD Economic Outlook (various years). Germany: up to and including 1991, western Germany; subsequent data concern the whole Germany.

Figure 2: Aggregate unemployment rate

However, this difference between the EU and the US is still more pronounced if we look at the low-skilled unemployment rate, as in Figure $3^{20}$. The situation in the EU and the US is quite similar up to the end of the 70's, but then completely diverges. The low-skilled situation worsens in EU countries, while it remains unchanged in the US.

On the contrary, if we look at the high-skilled unemployment rates, as in Figure $4^{21}$, we see that the situation on both sides of the Atlantic is much more similar. We also notice that the difference between the high-skilled and the aggregate unemployment rates is more or less constant. As a conclusion, the rise in the aggregate EU unemployment rate can be mainly explained by the surge of the low-skilled unemployment rate.

\footnotetext{
${ }^{20}$ In fact, we look at the difference between the low-skilled and the aggregate unemployment rates. Since we do not have homogeneous data, the definition of the low-skilled can be different across countries and some series are not updated. However this gives a reasonable picture of the situation.

${ }^{21} \mathrm{We}$ look at the difference between the high-skilled and the aggregate unemployment rates. Again, we do not have homogeneous data and the definition of the high-skilled can be different across countries. For instance, in US and Germany we only consider people with a university degree (small share of the population), whereas in Belgium we also include people with upper secondary education (larger share of the population).
} 


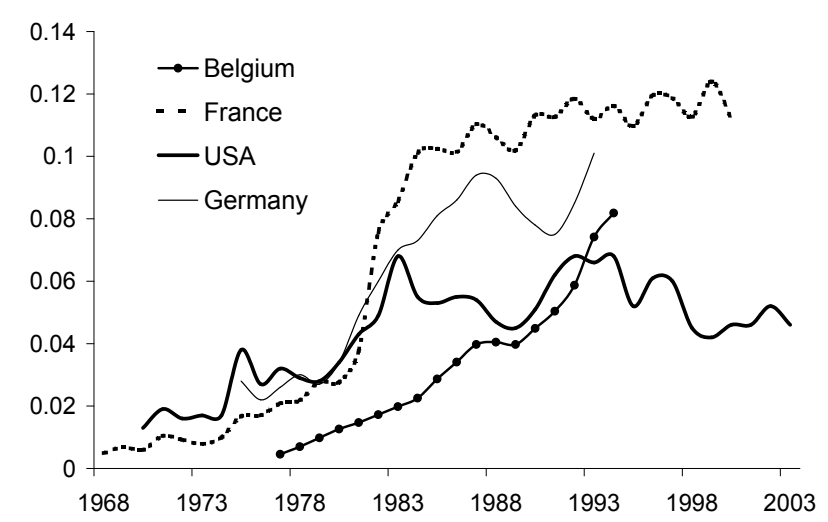

US, low-skilled: less than high-school diploma, source: Bureau of Labor Statistics. Germany, low-skilled: less than secondary education, source: Buttler and Tessaring (1993), western Germany only. France, low-skilled: non qualified blue and white collars, source: Fonseca, Maillard, and Sneessens (1998). Belgium, low-skilled: at most lower secondary education, source: Sneessens and Shadman (2000).

Figure 3: Low-skilled unemployment rate (difference with the aggregate unemployment rate)

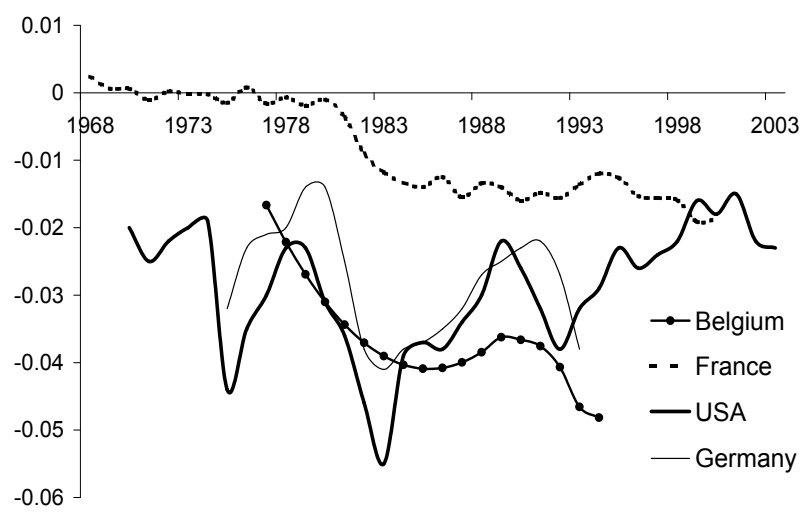

US, high-skilled: bachelor's degree and higher, source: Bureau of Labor Statistics. Germany, high-skilled: university, source: Buttler and Tessaring (1993), western Germany only. France, high-skilled: qualified blue and white collars, source: Fonseca, Maillard, and Sneessens (1998). Belgium, high-skilled: at least upper secondary education, source: Sneessens and Shadman (2000).

Figure 4: High-skilled unemployment rate (difference with the aggregate unemployment rate) 
Figure 5 shows that the evolution of relative wages is also quite different in the EU countries and in the US. For different reasons (downward wage rigidities induced by minimum wage legislation, collective agreements negotiated by powerful trade unions, ...), the wage dispersion in the EU remained constant (or even decreased) from end 70's to mid 90's. In the US, wage dispersion strongly increased.

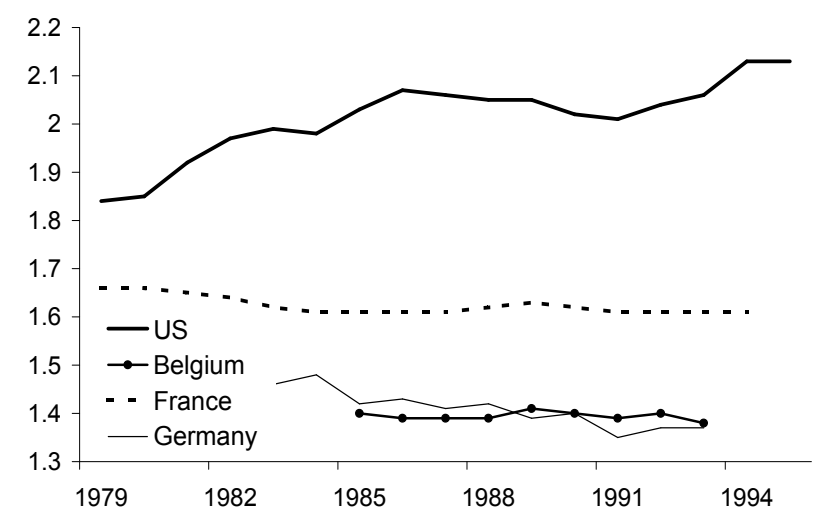

Gross D5/D1 ratio for males. Source: OECD (1996). Germany: western Germany only

Figure 5: Wage dispersion 